\section{Forschende \\ Komplementärmedizin}

Wissenschaft • Praxis • Perspektiven

\title{
The Tibetan Herbal Formula Padma Digestin in Functional Dyspepsia: An Open-Label Study
}

\author{
Rémy Meier ${ }^{\mathrm{a}}$ Peter Hengstler ${ }^{\mathrm{b}}$ Felix Weber ${ }^{\mathrm{c}} \quad$ Hermann Maurer $^{\mathrm{d}} \quad$ Cordelia Bommeli $^{\mathrm{e}}$ \\ Reto Brignoli ${ }^{f}$
}

a Department of Gastroenterology, Hepatology and Nutrition, Cantonal Hospital of Liestal,

${ }^{\text {b }}$ Praxis Gastroenterologie am Rosenberg,

${ }^{c}$ Praxis Dr. Weber,

${ }^{\mathrm{d}}$ Praxis Dr. Maurer, St. Gallen,

${ }^{\text {e }}$ Division of Thoracic Surgery, University Hospital Zurich,

f TRADYSER GmbH, Rüti, Switzerland

\section{Keywords}

Padma Digestin - Se 'bru 5 - Functional dyspepsia - Clinical study . Tibetan Medicine $\cdot$ Complementary and alternative medicine (CAM)

\section{Summary}

Background: The etiology of functional dyspepsia (FD) is multi-factorial. Its prevalence is high and it considerably impairs the patients' quality of life. The treatment options are limited. Padma Digestin, a multi-herbal formula from Tibetan Medicine, is traditionally used in malabsorption and dyspeptic symptoms as they do occur in FD, but as yet no clinical data exist on the formula. The aim of this study was to evaluate the safety, tolerability, and efficacy of Padma Digestin in patients with FD in a prospective, open clinical phase III trial. Patients and Methods: Patients were recruited by general practitioners, internists, and gastroenterologists and treated with $2 \times 3$ capsules of Padma Digestin daily for 6 weeks. Dyspeptic symptoms were analyzed using the Domestic/International Gastroenterology Surveillance Study (DIGEST) questionnaire extended by the 2 symptoms stomach cramps and lack of appetite. The quality of life was assessed using the Psychological General Well-Being Index (PGWBI-S) questionnaire (short version). Results: 37 patients were admitted and efficacy could be assessed in 31. In the overall efficacy assessment, the Padma Digestin treatment led to a statistically highly significant reduction of the respective most bothersome symptom scores regarding frequency, severity, and impairment of daily activities $(p<0.01)$. The treatment also led to significant improvements of the individual symptoms of postprandial fullness, nausea, localized and diffuse epigastric pain, stomach cramps, and lack of appetite. The onset of improvement was after a median of 7 days; time until disappearance of the symptoms was after a median of 22 days. The global efficacy and tolerability were rated as good or very good by the doctors and the patients in $84 \%$ and $78 \%$, respectively. The PGWBI-S increased from $55 \pm 19.5 \%$ to $70.5 \pm 15.5 \%$, which is nearly the normal value $(73.5 \pm$ $15.4 \%)$. As for safety, 11 patients reported a total of 17 adverse events $(A E), 1$ of which was serious but unrelated to the study medication. The $A E$ were mild or moderate. The safety laboratory data showed no statistically significant or otherwise relevant changes. Conclusions: The results show that the formula Padma Digestin has a high tolerability and efficacy in FD symptoms and positively influences psychological well-being and thus quality of life. It therefore represents a much needed extension of the therapeutic repertoire in FD.

\section{Schlüsselwörter}

Padma Digestin · Se 'bru 5 - Funktionelle Dyspepsie · Klinische Studie . Tibetische Medizin · Komplementär- und Alternativmedizin (CAM)

\section{Zusammenfassung}

Hintergrund: Die Ätiologie der funktionellen Dyspepsie (FD) ist multifaktoriell. Ihre Prävalenz ist hoch und sie führt zu einer starken Beeinträchtigung der Lebensqualität der Patienten. Die Behandlungsoptionen sind limitiert. Padma Digestin, eine komplexe Pflanzenformel aus der Tibetischen Medizin, wird traditionell bei Malabsorption und dyspeptischen Symptomen eingesetzt, wie sie bei FD auftreten. Bislang liegen keine klinischen Daten zu dieser Rezeptur vor. Ziel dieser Arbeit war die Evaluation der Sicherheit, Verträglichkeit und Wirksamkeit von Padma Digestin bei Patienten mit FD mittels einer offenen, prospektiven, klinischen Phase-IIIStudie. Patienten und Methoden: Die Patienten wurden durch Allgemeinpraktiker, Internisten und Gastroenterologen rekrutiert und während 6 Wochen mit $2 \times 3$ Kapseln Padma Digestin täglich behandelt. Die dyspeptischen Symptome wurden mit dem um die 2 Symptome Magenkrämpfe und Appetitmangel erweiterten Domestic/International Gastroenterology Surveillance Study (DIGEST)-Fragebogen analysiert. Die Lebensqualität wurde mittels des Psychological-General-Well-Being-Index(PGWBI-S)-Fragebogens (Kurzversion) evaluiert. Ergebnisse: 37 Patienten wurden eingeschlossen, und die Wirksamkeit konnte bei 31 beurteilt werden. In der Gesamtbeurteilung führte Padma Digestin zu einer statistisch hochsignifikanten Reduktion des jeweils am störendsten empfundenen Symptoms bezüglich Häufigkeit, Intensität und Beeinträchtigung der täglichen Aktivität $(p<0,01)$. Die Behandlung mit Padma Digestin führte außerdem zu einer signifikanten Verbesserung der Symptome postprandiales Völlegefühl, Nausea, lokalisierter und diffuser epigastrischer Schmerz, Magenkrämpfe und Appetitmangel. Eine Verbesserung wurde im Median nach 7 und ein Verschwinden der Symptome nach 22 Tagen beobachtet. Die globale Wirksamkeit und Verträglichkeit wurde durch die Ärzte und die Patienten bei $84 \%$ bzw. $78 \%$ als gut oder sehr gut bewertet. Der PGWBI-S stieg von $55 \pm$ $19,5 \%$ auf $70.5 \pm 15,5 \%$, was annähernd dem Normwert entspricht $173.5 \pm$ $15,4 \%$ ). Bezüglich der Sicherheit wurden bei 11 Patienten insgesamt 17 unerwünschte Ereignisse (UE) gemeldet, wobei eines davon schwerwiegend, jedoch ohne Zusammenhang mit der Studienmedikation war. Die UE waren mild oder moderat. Die Scherheitslabordaten zeigten keine statistisch signifikanten oder anderweitig relevanten Veränderungen. Schlussfolgerungen: Die Resultate zeigen, dass die Formel Padma Digestin eine hohe Verträglichkeit und Wirksamkeit bei funktionellen dyspeptischen Beschwerden aufweist. Sie beeinflusst das psychische Wohlbefinden und damit die Lebensqualität positiv. Das Präparat stellt daher eine dringend benötigte Erweiterung des therapeutischen Repertoires bei FD dar.

\section{KARGER \\ Fax +497614520714 \\ Information@Karger.com} www.karger.com (c) 2013 S. Karger GmbH, Freiburg

1661-4119/13/0208-0002\$38.00/0

Accessible online at:

www.karger.com/fok
Prof. Dr. Rémy Meier

Department of Gastroenterology, Hepatology and Nutrition

Cantonal Hospital of Liestal

Rheinstrasse 26, 4410 Liestal, Switzerland

remy.meier@ksli.ch 


\section{Introduction}

Functional gastrointestinal disorders such as functional dyspepsia (FD) are the most common diseases seen by gastroenterologists [1]. FD is defined as the occurrence of 1 or more specific dyspeptic symptoms over at least 3 months without any detectable structural or organic causes $[2,3]$. Symptoms include, e.g., epigastric discomfort or pain, early satiety, postprandial fullness, bloating, eructation, heartburn, nausea, and vomiting. Although it has no effect on mortality [4], FD considerably affects the quality of life of the patients. The disease has a high prevalence of up to $45 \%$ in the general population [5] and causes direct and indirect costs through treatment and by increasing absenteeism and reducing productivity [6]. It thus also poses a significant socioeconomic burden.

The pathogenesis is not completely known. However, it seems to be a multi-factorial disease in which disturbed gastrointestinal motility, hypersensitivity of the gut, the enteral immune status, and Helicobacter pylori infection seem to be involved. Additionally, psychosocial aspects seem to play an important role in FD [7].

Treatment usually follows a trial and error-based approach that uses, e.g., antacids, histamine $\mathrm{H}_{2}$ receptor antagonists, H. pylori eradication, and proton pump inhibitors (PPIs). In persisting dyspeptic symptoms, further treatment options are, e.g., prokinetics, spasmolytics, antidepressants, dietary changes, and psychotherapy $[8,9]$.

Because of the high prevalence, the impact on the quality of life, and the economic importance, safe and effective therapies are needed. Such approaches may come from complementary and alternative medicine (CAM), and especially from phytotherapy.

Herbal medicines contain a wide variety of active substances in very small doses. They can act synergistically and target multiple different pathophysiological pathways simultaneously [10]. Such multi-target drugs are also called network remedies. Usually, they have a high tolerability and are thus especially appropriate in multi-factorial, chronic diseases such as functional gastrointestinal disorders [11].

One such herbal medicine is Padma Digestin ${ }^{\circledR}$, a polyherbal formula produced in Switzerland according to international pharmaceutical guidelines. The preparation is based on the traditional Tibetan formula Se 'bru 5 and contains 5 herbs (composition see Patients and Methods). Se 'bru 5 has been used in the Himalayas for hundreds of years, mainly for digestive problems and malabsorption, but also in lower abdominal and back problems such as sexual dysfunction, recurrent cystitis, or lower back pain. Moreover, Se 'bru 5 is also known to balance 'wind disturbances', which can be understood as emotional and psychological upset.

The preparation Padma Digestin is licensed as a drug in Switzerland (Swissmedic No. 59375) and is available under the same name in various European countries, where it has been used for over 20 years in dyspeptic symptoms such as epigastric pressure, postprandial fullness, bloating, and flatulence, as well as for lack of appetite, e.g., in convalescence or old age. Some of the ingredients are known to be effective in digestive problems [12-14] and the whole formula has shown effects on gastrointestinal motility [15]. Nevertheless, to our knowledge there are no studies on the clinical effects of the preparation as a whole formula. The aim of this study was therefore to evaluate the safety and tolerability of the formula and to collect data on the efficacy of Padma Digestin in FD symptoms.

\section{Patients and Methods}

\section{Study Design and Setting}

This study is a prospective, multi-center, open-label, baseline-controlled clinical trial involving patients with FD. The study was approved by the local ethics committees and by the Swiss health authorities Swissmedic (reference number 2007DR3283) and conducted according to Good Clinical Practice (GCP) guidelines and local regulations. Patients were recruited by general practitioners, internists, and gastroenterologists in the Cantons of St. Gallen and Appenzell Ausserrhoden, Switzerland.

\section{Patients}

Inclusion criteria were the diagnosis of FD, with the presence of a minimum of 2 of the symptoms 1-11 from the Domestic/International Gastroenterology Surveillance Study (DIGEST) questionnaire [16, 17] for at least 4 weeks, with a frequency of at least once weekly and a severity score of at least 'moderate'. Additional criteria were an age of $>18$ and $<65$ years, the willingness and ability to comply with the trial requirements, and written informed consent. Exclusion criteria were organic gastrointestinal diseases (excluded by endoscopy), abdominal surgery within the last 6 months, food allergies, and treatment with potentially ulcerogenic drugs. Women at child-bearing age without a secure contraception method and pregnant or breastfeeding women were excluded, as were $>$ $20 \%$ out-of-range blood parameters. Further exclusion criteria were a treatment of FD within the last 4 weeks, e.g. with $\mathrm{H}_{2}$ receptor antagonists, PPIs, prokinetics, or antidepressants.

\section{Study Protocol and Data Collection}

Patients were treated with Padma Digestin, $2 \times 3$ capsules daily orally, for 6 weeks.

Data were collected at the initial visit (V1, baseline), at a second visit (V2) after 3 weeks, and at the final visit (V3) at the end of treatment. 4 weeks later, the patients were asked to complete a follow-up form asking about the further development of the symptoms, general health, and the need for further medication for dyspeptic symptoms.

\section{Safety and Tolerability}

The tolerability was assessed by doctors and patients separately. Adverse events (AE) were registered at each visit. At V1 and V3, routine hematology and blood chemistry assessments were performed. If applicable, the patients were asked to compare the present treatment to previous therapies for FD regarding efficacy and tolerability.

\section{Efficacy}

The effect on dyspeptic symptoms was analyzed using the DIGEST questionnaire $[16,17]$, which covers questions on the 3 dimensions frequency, intensity, and interference with activities of daily life of the following 14 symptoms: postprandial fullness, early satiety, nausea, vomiting, localized and diffuse epigastric pain, heartburn, regurgitation, eructation, fasting/nocturnal pain, bloating, lower abdominal pain, diarrhea, and constipation. Because of the traditional indication and clinical experiences, for the present study the list was extended to include stomach cramps and lack of appetite. Additionally, the highest score of any symptom regarding all 3 dimensions was analyzed to assess changes in the most bothersome aspects of the dyspeptic symptoms. Clinical overall efficacy was assessed by doctors and patients separately, and the patients were 
asked about the time until the onset of improvement and, if applicable, time to absence of symptoms. Quality of life parameters were assessed using the short version of the Psychological General Well-Being Index (PGWBI-S), which is a validated short version of the PGWBI questionnaire [18] including 6 questions.

\section{Study Medication}

Padma Digestin (Swissmedic Nr. 59375) was provided by Padma Inc., Hinwil, Switzerland, which produces the product in Switzerland according to Good Manufacturing Practice (GMP) standards. The herbal preparation is based on the classical formula Se 'bru 5 from Tibetan Medicine. 1 capsule contains $204 \mathrm{mg}$ pomegranate seeds (Punica granatum L.), 102 $\mathrm{mg}$ lesser galangal rhizome (Alpinia officinarum Hance), $25.5 \mathrm{mg}$ long pepper fruit (Piper longum L./P. retrofractum Vahl.), $12.75 \mathrm{mg}$ cardamom seeds (Elettaria cardamomum Maton var. Miniscula Burkill), and 12.75 $\mathrm{mg}$ cassia bark (Cinnamomum aromaticum $\mathrm{Nees}$ ).

\section{Statistical Analysis}

A descriptive analysis is provided for safety and efficacy parameters as well as for patient demography. Data are presented either as natural numbers or as mean \pm standard deviation (SD) and compared to baseline with Armitage's chi-squared test for trend or paired t-test. The significance threshold of all statistical tests is a two-sided $5 \%$.

\section{Results}

\section{Disposition of Patients}

In 7 centers, 37 patients (safety population) were screened and included. The intention-to-treat (ITT) group comprises 31 patients with at least 1 efficacy assessment, of which 30 completed the trial. 9 patients had minor protocol violations and 22 completed the study as per protocol (PP).

\section{Demographics}

The ITT group included 18 women and 13 men with a median age of $43 \pm 14$ years, a body mass index (BMI) of $24 \pm 5$ $\mathrm{kg} / \mathrm{m}^{2}$ and with acceptable hematology, routine blood biochemistry values, and vital signs.

\section{Efficacy}

For efficacy analysis, the data of the ITT group are described; the PP data give comparable results. As an overall assessment and to evaluate the most bothersome aspects of the disease, the highest scores in frequency, severity, and impairment of daily activities were analyzed in each patient. Padma Digestin treatment led to a significant reduction in all 3 dimensions $(\mathrm{p}<0.01)$. Regarding global efficacy, both the doctors and the patients found an improvement by Padma Digestin in $84 \%$ of the patients (fig. 1). In the individual symptoms, Padma Digestin led to a significant improvement of postprandial fullness and nausea regarding all dimensions $(\mathrm{p}<0.01)$, in localized and diffuse epigastric pain (frequency $\mathrm{p}<0.01$, severity and impairment of daily activities $\mathrm{p}<0.05$ ) and in stomach cramps and lack of appetite (frequency $\mathrm{p}<0.01$ and $<0.05$, respectively; other parameters $\mathrm{p}<0.05)$. A trend for improvement was seen in early satiety, fasting or nocturnal pain, bloating and constipation $(\mathrm{p}<0.1)$. In the other

\section{Assessment of global tolerability and efficacy of Padma Digestin treatment $(n=31)$}

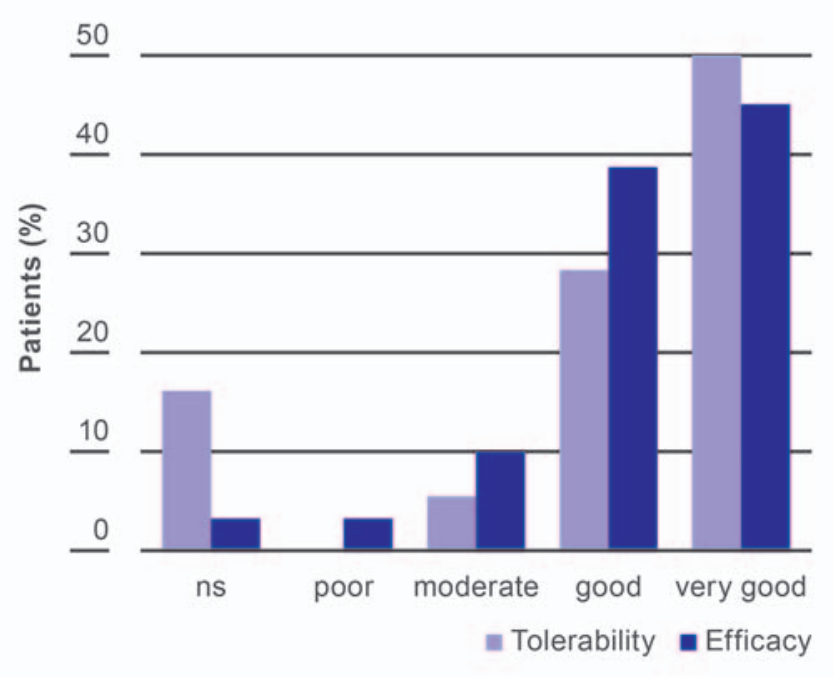

Fig. 1. Global assessment of tolerability and efficacy of Padma Digestin in FD symptoms (mean of the assessments by doctors and patients; ns = not stated).

symptoms of the questionnaire, no significant change was observed (fig. 2).

The questions about the onset of improvement and the time to absence of symptoms were answered by 23 (74\%) and $13(42 \%)$ of the patients, respectively. Onset of improvement was after a median of 7 days; time until disappearance of the symptoms was after a median of 22 days.

The impairment of daily activities was rated as severe or very severe by $42 \%$, as mild or moderate by $45 \%$, and as nonexistent by $13 \%$ of the patients at V1. At V3, these numbers were $19 \%, 23 \%$, and $55 \%$ respectively (fig. 3 ). This improvement was also reflected in an increase in the quality of life. The PGWBI-S improved from $55 \pm 19.5 \%$ to $70.5 \pm 15.5 \%$ (p $<0.001)$. Of the 6 parameters, 'cheerfulness' and 'exhausted and worn out' improved most.

Of the 21 patients with other, previous therapies for FD, $62 \%$ and $43 \%$ rated the treatment with Padma Digestin better regarding efficacy and tolerability, respectively (fig. 4).

\section{Safety}

Global tolerability was assessed as good or very good in $81 \%$ of the cases by the doctors and in $76 \%$ by the patients (mean 78\%) (fig. 1).

11 patients reported a total of $17 \mathrm{AE}, 1$ of which was serious but unrelated to the study medication. This concerned a patient who had been included despite a major violation of admission criteria of an age of 85 years and in whom a preexisting but not detected pancreatic cancer was diagnosed during the study. The patient was allocated to the safety group. Of the other AE, the causality with the treatment was rated as probable in 2 patients ( 1 with flatulence and constipation, 1 with eructation, both withdrawals), as possible in $8 \mathrm{AE}$ (pruritus 2, headache 3 (1 withdrawal) and diarrhea, increased liver laboratory parameters, parageusia, 1 each), and as un- 
Fig. 2. Reduction of the number of patients with relevant severity of dyspeptic symptoms (severe or very severe) in \%, at baseline and after 6 weeks of Padma Digestin treatment.

\section{Number of patients afflicted with the symptom in relevant severity (severe or very severe) before and after Padma Digestin treatment in \% (ITT $n=31$ )}

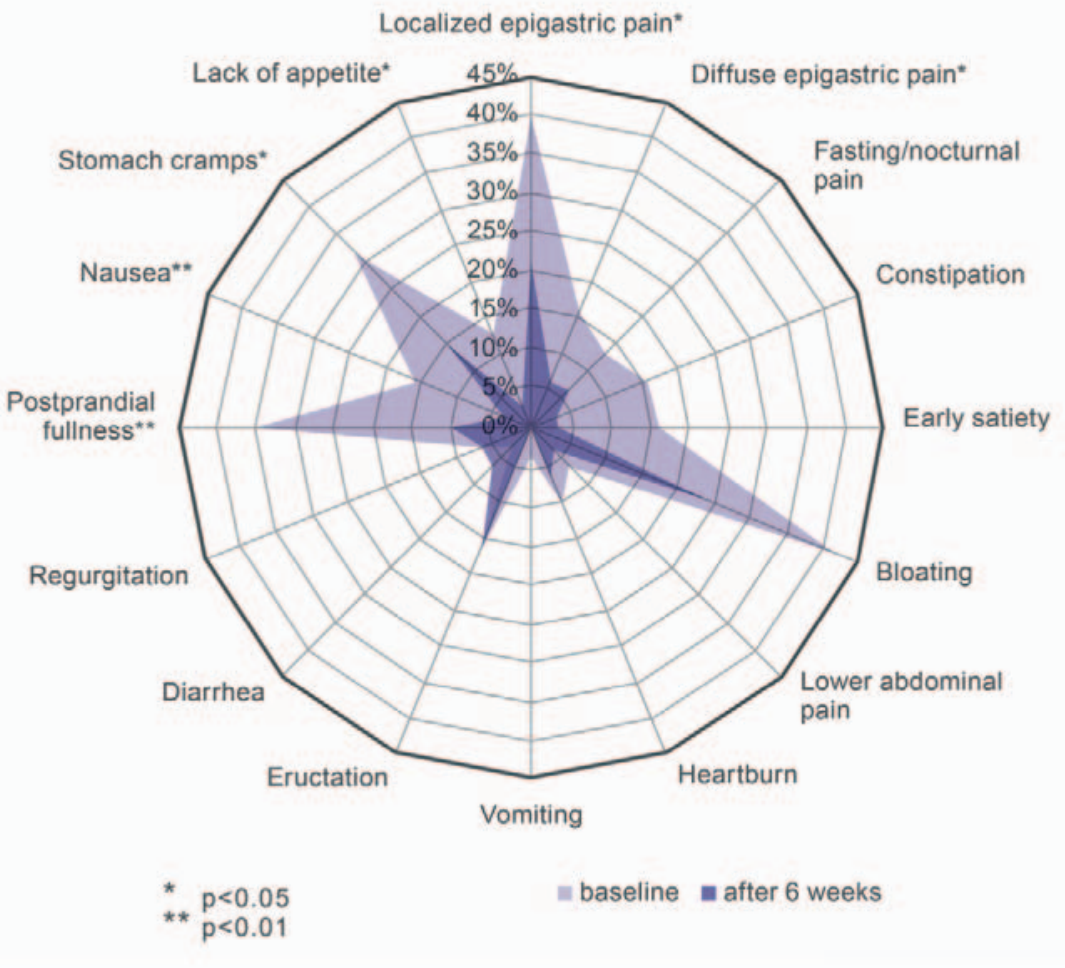

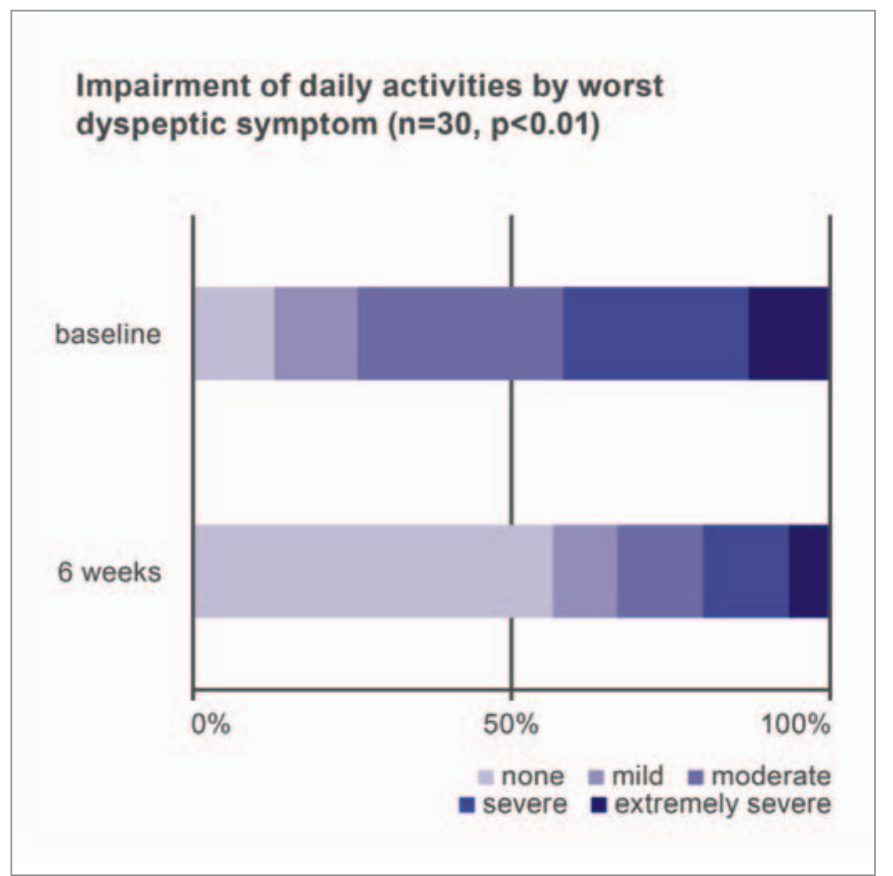

Fig. 3. Maximal impairment of activities of daily life by the worst dyspeptic symptom at baseline and after 6 weeks of Padma Digestin treatment.

\section{Comparison of Padma Digestin with earlier other treatments for functional dyspepsia $(n=21)$}

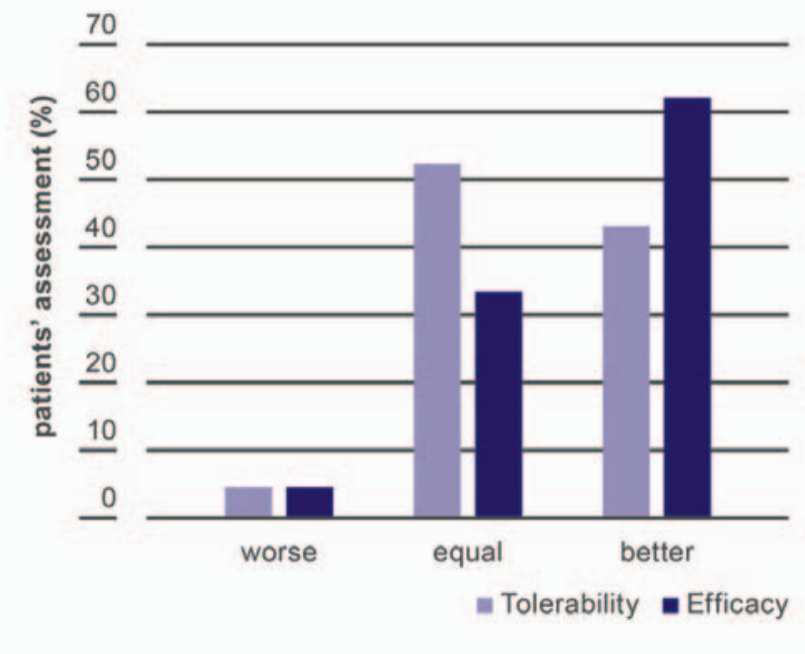

Fig. 4. Patients with previous treatments for functional dyspepsia compared the tolerability and efficacy of Padma Digestin with other therapies regarding tolerability and efficacy. 
likely in $3 \mathrm{AE}$ (1 withdrawal with labyrinthitis and nausea, 1 diarrhea). No relationship was stated for 1 case each of sore throat and cystitis. The vital parameters did not show any clinically relevant differences between start and end of treatment. The mean changes were in systolic blood pressure $(\mathrm{BP})+3.9$ $\mathrm{mmHg}(-20$ to $+54 \mathrm{mmHg})$, diastolic $\mathrm{BP}-1.3 \mathrm{mmHg}(-28$ to $+17 \mathrm{mmHg})$, heart rate $+4.5 \mathrm{bpm}(-15$ to $+25 \mathrm{bpm})$ and weight $-0.8 \mathrm{~kg}(-5$ to $+6 \mathrm{~kg})$. In 4 cases, the systolic BP and in 3 cases the diastolic BP rose above the upper limit, but these were not reported as AE. In 2 cases each, the systolic and diastolic BP decreased from high to normal values during the trial. The safety laboratory data showed no statistically significant differences between V1 and V3. No shift was detected in hemoglobin, erythrocytes, thrombocytes, aspartate aminotransferase (ASAT), and creatinine. 4 patients had leucopenia at admission, which had recovered at V3.

\section{Withdrawals and Exclusions}

There were 6 withdrawals or exclusions after V1; the reasons were violation of admission criteria (1), violation of admission criteria and AE (1), stop due to lack of efficacy or AE (3), and lack of compliance (1). 1 further patient was excluded after V2 due to lack of compliance, i.e. a major protocol violation.

\section{Discussion}

Probably due to the fact that an endoscopy was mandatory to exclude structural diseases, the recruitment of patients was slow. This led to a relatively small sample size, which is one limitation of this study. The other is the open design, which allows the rate of placebo responders only to be assessed in comparison to the literature, as is discussed below.

The AE in this study were mild or moderate and there were no serious AE attributed to the study medication. Only $2 \mathrm{AE}$ were rated as 'probably' related to the study medication ( 1 case of constipation and flatulence, 1 case of eructation). There were no systematic or significant changes of the vital parameters, the hematological or the blood chemistry variables. The only noteworthy finding was a normalization of an initial leucopenia in 4 patients. The preparation therefore demonstrated a favorable safety profile and the global tolerability of the treatment was assessed as good or very good by the majority of the patients and the doctors (fig. 1).

FD is characterized by its heterogeneity of symptoms. Padma Digestin showed an efficacy in various symptoms; improvements were observed especially in postprandial fullness, nausea, localized and diffuse epigastric pain, stomach cramps, and lack of appetite. The clinical effects on different digestive symptoms support the hypothesis that Padma Digestin acts according to a multi-target mode of action, as is characteristic of multi-compound formulas from Tibetan Medicine [19]. Such multi-level mechanisms seem to be well suited to treat diseases with complex etiology such as functional digestive disorders, for which an effectiveness has been shown not only for Tibetan formulas but also for other multi-herbal medicines, e.g. from Japanese Kampo medicine, Chinese medicine or from a European context [20-23].
The various substance groups in the herbal ingredients of Padma Digestin, such as flavonoids, pungent and mucilaginous substances, essential oils, fruit and fatty acids, and tannins, are known to be effective in different pathogenic factors in FD. Among others, they have bactericidal effects against $H$. pylori as well as gastroprotective, spasmolytic and carminative activities $[24,25]$. They also seem to influence gastrointestinal motility in ways that promote gastric emptying and intestinal absorption $[15,26]$. The antiemetic properties of gingerols could explain the reduction in nausea [27]. Gingerols and other substances contained in Padma Digestin, such as galangins, piperine, and cinnamaldehyde, are known to act on transient receptor potential (TRP) ion channels and, via desensitization, may reduce hypersensitivity of the gut. TRP agonists also modulate smooth muscle contractility and thus influence gastrointestinal motility and peristalsis $[15,28,29]$.

Additionally to the individual symptoms, an overall efficacy could also been shown in the reduction of the highest scores in frequency, severity, and impairment of daily activities, which signifies an improvement of the most bothersome aspects of the disease. This is confirmed by the positive overall rating of the efficacy. The improvement in $84 \%$ of the cases clearly exceeds the placebo response rate of $20-60 \%$ that is usually seen in studies on FD [30]. The improvement of the symptoms was also reflected in an increase of the quality of life. The PGWBI-S improved from $55 \pm 19.5 \%$ to $70.5 \pm$ $15.5 \%$, which is near to the mean value of $73.5 \pm 15.4 \%$ measured in healthy controls [31].

Various factors such as the multi-factorial etiology, the chronicity, and the heterogeneity of the symptoms make FD difficult to treat. The therapy is usually probationary and symptom-oriented, which leads to many patients having a history of unsuccessful treatment attempts. The majority of the patients who were able to compare the Padma Digestin treatment to earlier therapies judged Padma Digestin as more efficient than previous therapies (fig. 4).

Although FD is a benign disease, it is still clinically relevant. Because of its high prevalence and the limited treatment options, it generates direct and indirect costs. By increasing absenteeism and reducing productivity $[5,6]$, the disease has major socioeconomic consequences, and safe and effective therapies are urgently needed.

\section{Conclusions}

The present study shows the polyherbal formula Padma Digestin to be a safe and effective treatment in FD disorders, especially in postprandial fullness, localized and diffuse epigastric pain, nausea, stomach cramps, and lack of appetite. The preparation is well tolerated. The results support the traditional application of the formula being used in functional digestive disorders of the upper gastrointestinal tract as well as in lack of appetite and nausea. Although further studies are needed to confirm these results, Padma Digestin can be valued as a safe and effective therapeutic option in the treatment of FD disorders. 


\section{Acknowledgements}

The study medication was produced and supplied by Padma Inc., Switzerland. The authors want to thank the other investigators, Dr. med. Ram Anand, Benken; Dr. med. Dominique Kähler, Wil; Dr. med. Marcel Schmuki, St. Gallen; Dr. med. Hanspeter Sonderegger, Trogen, Switzerland, for their contribution of patient data. Additionally, we thank Dr. Enzo Grossi, Italy, for allowing us to use the short version of the PGWBI questionnaire as validated by his group.

\section{Disclosure Statement}

At the time of study performance, C.B. was an employee of Padma Inc. Otherwise the authors declare no conflict of interest.

\section{References}

1 Hammer J, Eslick GD, Howell SC, Altiparmak E, Talley NJ: Diagnostic yield of alarm features in irritable bowel syndrome and functional dyspepsia. Gut 2004;53:666-672.

2 Rome Foundation: ROME III diagnostic criteria for functional gastrointestinal disorders. Appendix A. Rome Foundation, www.romecriteria.org, 2012: 885-897.

$\checkmark 3$ Drossman DA: The functional gastrointestinal disorders and the Rome III process. Gastroenterology 2006;130:1377-1390.

4 Chang JY, Locke GR 3rd, McNally MA, Halder SL, Schleck CD, Zinsmeister AR, Talley NJ: Impact of functional gastrointestinal disorders on survival in the community. Am J Gastroenterol 2010; 105:822-832.

$\checkmark 5$ Camilleri M, Dubois D, Coulie B, Jones M, Kahrilas PJ, Rentz AM, Sonnenberg A, Stanghellini V, Stewart WF, Tack J, Talley NJ, Whitehead W, Revicki DA: Prevalence and socioeconomic impact of upper gastrointestinal disorders in the United States: results of the US Upper Gastrointestinal Study. Clin Gastroenterol Hepatol 2005;3:543-552.

6 Brook RA, Kleinman NL, Choung RS, Melkonian AK, Smeeding JE, Talley NJ: Functional dyspepsia impacts absenteeism and direct and indirect costs. Clin Gastroenterol Hepatol 2010;8:498-503.

7 Sanger GJ, Chang L, Bountra C, Houghton LA: Challenges and prospects for pharmacotherapy in functional gastrointestinal disorders. Ther Adv Gastroenterol 2010;3:291-305.

8 Talley NJ, Choung RS: Whither dyspepsia? A historical perspective of functional dyspepsia, and concepts of pathogenesis and therapy in 2009. J Gastroenterol Hepatol 2009;24(suppl 3):S20-S28.

9 Gschossmann J, Vennos C: Funktionelle Verdauungsstörungen: multimodale Wirkung von Padma Digestin. Ars Med 2012;4:191.

10 Saller R, Melzer J: Multimorbidität und MultiTarget-Therapie in der Phytotherapie. Forsch Komplementmed 2013;20(suppl 2):1.

11 Wagner H: Multitarget therapy - the future of treatment for more than just functional dyspepsia. Phytomedicine 2006;13(suppl 5):122-129.

12 Chaurasia N: Cinnamomum; in Blaschek W, Ebel S, Hackenthal E, Holzgrabe U, Keller K, Reichling J, Schulz V (eds): HagerROM 2006: Hagers Handbuch der Drogen und Arzneistoffe (CD-ROM). Heidelberg, Springer Medizin, 2006.
13 Hölzl J, Juretzek W, Schneider G, Stahl-Biskup E: Piper; in Blaschek W, Ebel S, Hackenthal E, Holzgrabe U, Keller K, Reichling J (eds): HagerROM 2006: Hagers Handbuch der Drogen und Arzneistoffe (CD-ROM). Heidelberg, Springer Medizin, 2006.

14 Braun-Sprakties U: Elettaria; in Blaschek W, Ebel S, Hackenthal E, Holzgrabe U, Keller K, Reichling J, Schulz V (eds): HagerROM 2006: Hagers Handbuch der Drogen und Arzneistoffe (CD-ROM). Heidelberg, Springer Medizin, 2006.

15 Balsiger BM, Krayer M, Rickenbacher A, Flogerzi B, Vennos C, Gschossmann JM: Tibetan herbal formula Padma Digestin modulates gastrointestinal motility in vitro. World J Gastrointest Pharmacol Ther 2013;4:9-15.

16 Eggleston A, Farup C, Meier R: The Domestic/International Gastroenterology Surveillance Study (DIGEST): design, subjects and methods. Scand J Gastroenterol 1999;231:9-14.

17 Meier R, Beglinger C, Moser N, Meyer M, Brignoli R: Validierung des 'Digest-Fragebogens' auf Konsistenz und Reproduzierbarkeit bezüglich Oberbauchsymptomen. Schweiz Med Wochenschr 1998; 128:880-886.

18 Grossi E, Groth N, Mosconi P, Cerutti R, Pace F, Compare A, Apolone G: Development and validation of the short version of the Psychological General Well-Being Index (PGWBI-S). Health Qual Life Outcomes 2006:4:88

19 Schwabl H, Vennos C, Saller R: Tibetische Rezepturen als pleiotrope Signaturen - Einsatz von Netzwerk-Arzneien bei Multimorbidität. Forsch Komplementmed 2013;20(suppl 2):35-40.

20 Sallon S, Ben-Arye E, Davidson R, Shapiro H, Ginsberg G, Ligumsky M: A novel treatment for constipation-predominant irritable bowel syndrome using Padma Lax, a Tibetan herbal formula. Digestion 2002;65:161-171.

21 Arai M, Matsumura T, Tsuchiya N, Sadakane C, Inami R, Suzuki T, Yoshikawa M, Imazeki F, Yokosuka O: Rikkunshito improves the symptoms in patients with functional dyspepsia, accompanied by an increase in the level of plasma ghrelin. Hepatogastroenterology 2012;59:62-66.
22 Xiao Y, Liu YY, Yu KQ, Ouyang MZ, Luo R, Zhao XS: Chinese herbal medicine liu jun zi tang and xiang sha liu jun zi tang for functional dyspepsia: meta-analysis of randomized controlled trials. Evid Based Complement Alternat Med 2012;2012: 936459.

23 Melzer J, Rösch W, Reichling J, Brignoli R, Saller R: Meta-analysis: phytotherapy of functional dyspepsia with the herbal drug preparation STW 5 (Iberogast). Aliment Pharmacol Ther 2004;20: 1279-1287.

24 Gilani AH, Jabeen Q, Khan A, Shah AJ: Gut modulatory, blood pressure lowering, diuretic and sedative activities of cardamom. J Ethnopharmacol 2008;115:463-472.

25 Mehmood MH, Gilani AH: Pharmacological basis for the medicinal use of black pepper and piperine in gastrointestinal disorders. J Med Food 2010;13: 1086-1096.

26 Khajuria A, Thusu N, Zutshi U: Piperine modulates permeability characteristics of intestine by inducing alterations in membrane dynamics: influence on brush border membrane fluidity, ultrastructure and enzyme kinetics. Phytomedicine 2002;9:224-231.

27 Haniadka R, Rajeev AG, Palatty PL, Arora R, Baliga MS: Zingiber officinale (ginger) as an antiemetic in cancer chemotherapy: a review. J Altern Complement Med 2012;18:440-444.

28 Holzer P: TRPV1 and the gut: from a tasty receptor for a painful vanilloid to a key player in hyperalgesia. Eur J Pharmacol 2004;500:231-241.

29 Mandadi S, Roufogalis BD: ThermoTRP channels in nociceptors: taking a lead from capsaicin receptor TRPV1. Curr Neuropharmacol 2008;6:21-38.

30 Talley NJ; American Gastroenterological Association: American Gastroenterological Association medical position statement: evaluation of dyspepsia. Gastroenterology 2005;129:1753-1755.

31 Chassany O, Dimenäs E, Dubois D, Wu A, Dupuy $\mathrm{H}$ : The Psychological General Well-Being Index (PGWBI) User Manual. Lyon, MAPI Research Institute, 2004. 